\title{
III. MYCORRHIZAE IN AGROFORESTRY: A CASE-STUDY
}

\author{
S.T. NUHAMARA*
}

Tropical Forest Biology Program, BIOTROP, Bogor, Indonesia

Keywords: Agroforestry, mycorrhiza, resin, Shorea javanica, Sumatra

\begin{abstract}
Census of mycorrhizae in Shorea javanica agroforests has been made periodically in the district of Krui, Lampung, Sumatra. Amanita hemibapha (Amanitaceae), Cantharellus cibarius (Cantharella-ceae), Lactarius spp., Russula spp. (Russulaceae) and Scleroderma sp. (Sclerodermataceae) were commonly encountered on the agroforest floor. These mycorrhizal fungi are naturally associated with the planted trees. The significance of mycorrhizae for the maximization of growth and sustained productivity of resin is discussed as well as the need to design well defined agroforestry systems to facilitate growth and to improve production management techniques.
\end{abstract}

\section{INTRODUCTION}

Torquebiau (1984) reported for the first time that the "kebun damar" or "resin garden" of Shorea javanica K \& V (Dipterocarpaceae) in Krui (Sumatra) was a typically good example of an agroforestry system for resin production.

To obtain the maximum sustained yield of resin, all the growth factors should be optimally maintained. Ideally, a tree is expected to perform active and continuous chemo-ecophysiological processes for long possible periods of time.

Mycorrhizae play an important role at root level by dynamizing the nutrients and water uptakes. In the case of an agroforestry system, two groups of mycorrhizae can be considered: those which are directly associated with the main crop and those which are not, and/or are associated with the other component species of the system.

In this paper, the author presents information related to the first group. Nevertheless, new ideas proposed about the second group and the specific case of mycorrhizae in agroforestry especially the inter-relationships between the above-ground organs, e.g. leaves and the mycorrhizal roots of the system, is discussed.

\section{MATERIAL AND METHODS}

Census of the occurrence of fruiting bodies of mycorrhizal fungi having connections with the roots of $S$. javanica has been made periodically at Krui,

\footnotetext{
* Present Address: Faculty of Forestry, Bogor Agricultural University, Darmaga Campus, Bogor, Indonesia.
} 
Lampung, Sumatra in June and October 1985 and February of 1986. The study sites were at Ngaras, Gunung Kemala and Pahmongan, all in the surroundings of Krui. Soil analysis corresponding to these sites was described by Sheehy Skeffington in Chapter 2 .

Taxonomic identifications were made at the BIOTROP Laboratory. This simple procedure was adopted from Bakshi (1974) and based on experience with other dipterocarp species either in Haurbentes, Jasinga, West Java or in Lempake, East Kalimantan. Interviews with the local farmers were also conducted especially relating to seedling preparation.

\section{RESULTS AND DISCUSSION}

Based on the periodical census made so far, the following, well-known, ectomycorrhizal fungi have been recorded:
Amanita hemibapha
Amanitaceae
Cantharellus cibarius
Cantharellaceae
Lactarius spp.
Russulacea
Russula spp.
Russulaceae
Scleroderma sp.
Sclerodermataceae

It was learnt from the local farmers that no artificial inoculation technique has been applied so far for mycorrhizal introduction in the agroforests.

Some of these mycorrhizal fungi have been artificially inoculated to Shorea pinanga, S. stenoptera and Hopea sangal (Nuhamara et al. 1986), and developed successfully. It was also concluded that infected soil as source of inoculum performed better as compared to single mycorrhizal fungus. This suggests the need for application of infected soil to a neighboring site when a crop is to be experimented. However, on a long term basis, especially when drastic changes in agricultural practices can be foreseen, the use of pure culture will be the only advisable measure.

Shorea javanica is a special case because as a resin producer, the plant is expected to produce continuously. This requires optimum chemo-ecophysiological processes. To do this, both the above ground organs (e.g. leaves) and the under ground ones (roots), must function optimally. There should be a reciprocal balance of processes. It is in connection with this that the roots should be well fortified by typical mycorrhizal associations, to enable them to absorb and accumulate nitrogen, phosphorus, potassium and calcium more rapidly and for longer periods of time than non mycorrhizal ones. Mycorrhizae, especially the ectomycorrhizae, appear to increase the tolerance of trees to drought, high soil temperatures, soil toxicity (organic and inorganic), and extreme low soil $\mathrm{pH}$ caused by high levels of sulfur or aluminium. Ectomycorrhizae deter infection of feeder roots by 
pathogens. Hormone induced or the production of which is induced by fungal symbionts cause ectomycorrhizal roots to have a greater longevity (duration of physiological activity) than non mycorrhizal roots (Marx 1973).

Sufficient water and other photosynthetic elements such as magnesium are essential for a proper functioning of the leaves. Furthermore, according to the way carbon is fixed, plants belong to one of the $\mathrm{C} 3, \mathrm{C} 4$ or CAM categories.

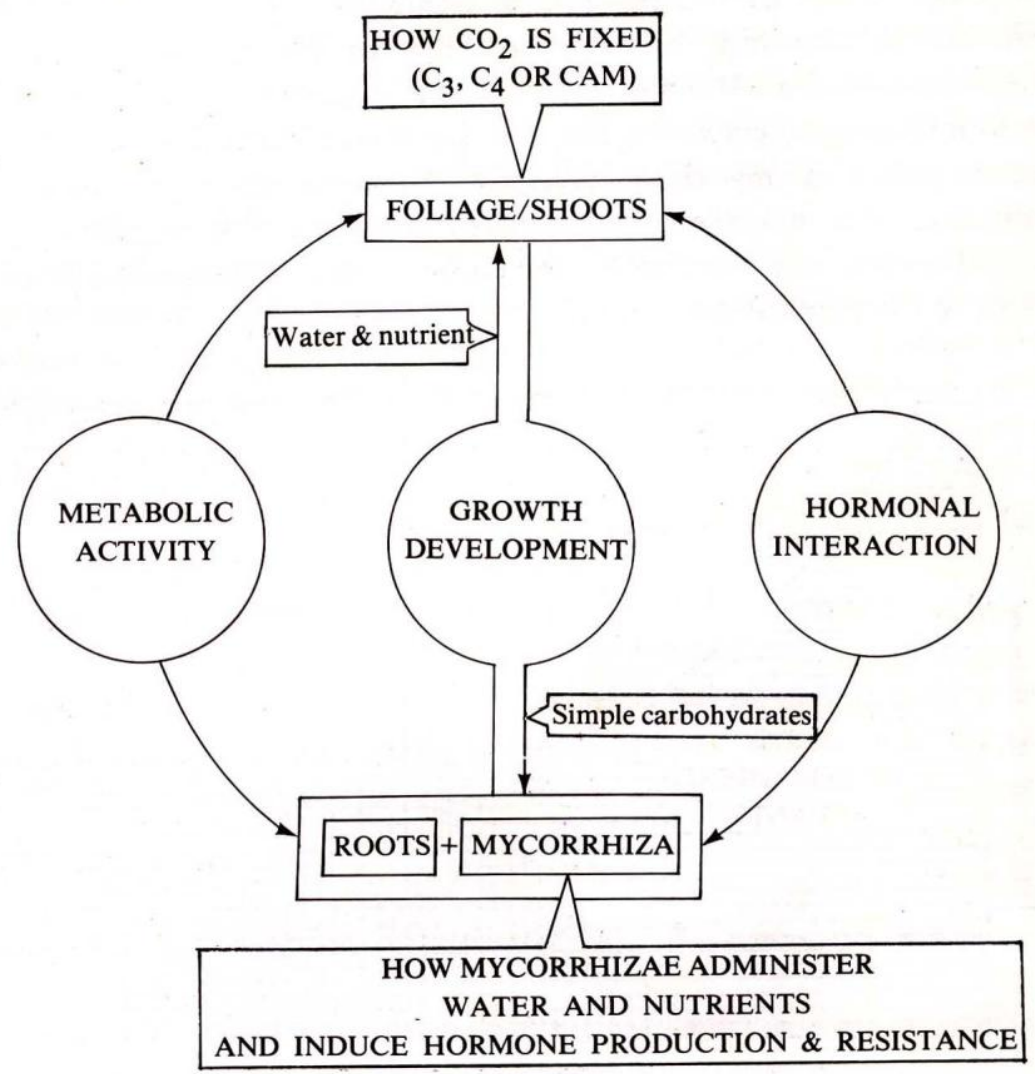

Figure 1. Chart showing the complex ecophysiological processes in plant growth and development in relation to mycorrhiza, and possible $\mathrm{CO} 2$ fixing ways.

This implies that the different carbohydrate productions which in turn determine the different available simple carbohydrates might alter the different mycobionts. This proposed complex metabolic pattern is illustrated in Fig. 1. As shown on the chart, the hormones, produced by or induced with the presence of mycorrhizae, activate the function of the rhizophere. Regarding agroforestry, it is possible to manipulate the species composition and structure (Michon 1983 and 
Torquebiau 1964) in such a way to facilitate the more stable eco-unit (Oldeman 1983) which is also of good economical value for the farmers. The author suggests to construct agroforestry systems having a good combination of C3 plants like S. javanica trees and other fruit trees and $\mathrm{C} 4$ plants in combination with CAM plants. It is believed that with such a mixed composition, a stable association can be obtained and productive compatibility achieved.

Another aspect of the possible manipulation of species in agroforestry concerns the relationships between host species diversity and the types of mycorrhizal association. The diagram of Fig. 2 suggests that the zone where ecto and endo-mycorrhizae coexist is the best for mixed gardening or agroforestry, because the richer the mycobiont diversity, the higher the degree of productive compatibility. This practice is common in many tropical regions, e.g. Java. Oldeman (Personal communication 1985) believed that such a model is stable and applicable to the tropical conditions.

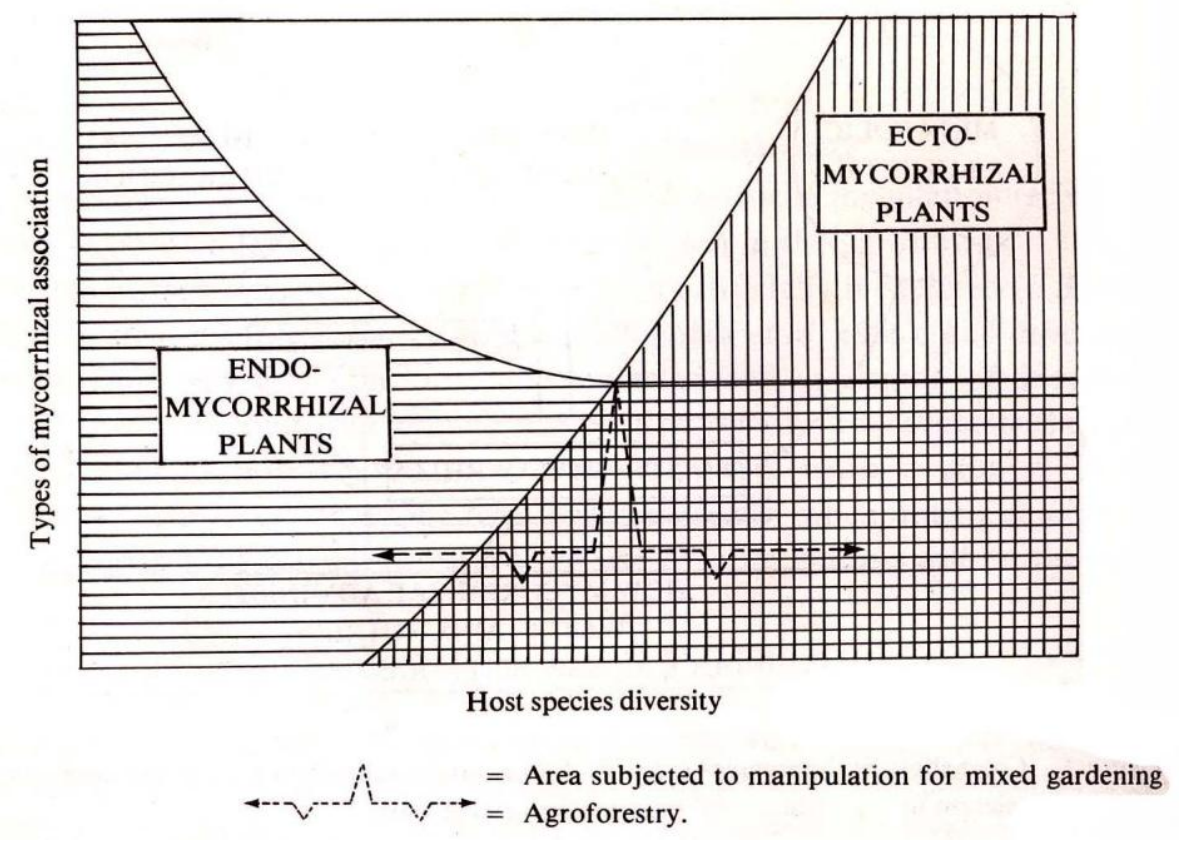

Figure 2. Theoretical curve showing the relationship between the host species diversity and the type of mycorrhizal association.

The problem is how far it is possible to change or manipulate the symbiont composition. Moving to the left of the figure would mean more endomycorrhizal plants and moving to the right a combination of ecto and endomycorrhizal plants. Most of the annual herbaceous agricultural crops are endomycorrhizal, like paddy, 
maize, soybean, etc, but some perennial woody agricultural crops such as coffee, cacao, oil palm are also endomycorrhizal plants. Contrarily, most forest trees such as dipterocarps and pines are associated with ectomycorrhizae and there are also some important tropical forest trees such as teak and Agathis which belong to endomycorrihizal plants.

Considering both the carbon metabolism and the mycorrhizal association of the plants, it must be possible to define the smallest agroforestry unit of good economical as well as ecological stability, and to propose it for development areas in different parts of the country. Optimizing intercropping in agroforestry would mean the organizing of species composition, density and structure of both woody and herbaceous plants in order to facilitate their complementary productivity and at the same time minimizing their competitive relationships.

In relation to resin production, it is suggested that further research be concentrated on tapping technique like its disturbance on the metabolic processes. The number and size of the scars affect the translocation of carbohydrates from the top down to the roots. This ultimately influences the availability of simple carbohydrates for the mycobionts.

\section{ACKNOWLEDGMENTS}

The author expresses his gratitude to Dr. E.F. Torquebiau, the French Expert seconded to BIOTROP for his generous stimulation, inspiration as well as his invaluable criticisms on the author's ideas whithout which this paper would not be in this form. Thanks are also due to Dr. Tri Binarko Suselo for his support and suggestions and to Mr. Koko Iskandar for technical assistance.

\section{REFERENCES}

BAKSHI, B.K. 1974. Mycorrhiza and its role in forestry. Forest Research Institute and Colleges, Dehra Dun, India. $89 \mathrm{pp}$.

MARX, D.H. 1973. Growth of ectomycorrhizal and non mycorrhizal short leaf pine seedlings in soil infested with Phytopthora cinnamomi, Phytopathology 63: 18-23.

MICHON, G. 1983. Village-Forest-Garden in West Java. In: Plant Research and Agroforestry. Edited by: P.A. Kuxley. International Council for Research in Agroforestry, Nairobi. 617 pp.

NUHAMARA, S.T., S. HADI and S.S. TJITROSOMO, 1986. The effect of different soil types and mycorrhizae on the growth of some dipterocarp seedlings. BIOTROP Spec. Publ. No. 26 (in press).

OLDEMAN, R.A.A. 1983. The design of ecologically sound agroforests. In: Plant Research and Agroforestry. Edited by: P.A. Huxley, International Council for Research in Agroforestry, Nairobi. $617 \mathrm{pp}$.

TORQUEBIAU, E.F. 1984. Man-made Dipterocarp Forest in Sumatra. Agroforestry Systems, 2: 103-127. 